\title{
Relação entre a inserção da Equipe de Saúde Bucal na Estratégia Saúde da Família e o nível de conhecimento dos agentes comunitários de saúde
}

\author{
Relation between the insertion of the Oral Health Team in the Family Health Strategy and the level of knowledge of community
} health workers

\section{Relación entre la inserción del Equipo de Salud Bucal en la Estrategia de Salud Familiar y el nivel de conocimiento de los agentes comunitarios de salud}

Ronald Jefferson Martins. Universidade Estadual Paulista Júlio de Mesquita Filho (UNESP). Araçatuba, SP, Brasil. rojema@foa.unesp.br (Autor correspondente)

Suzely Adas Saliba Moimaz. Universidade Estadual Paulista Júlio de Mesquita Filho (UNESP). Araçatuba, SP, Brasil. sasaliba@foa.unesp.br Artênio José Ísper Garbin. Universidade Estadual Paulista Júlio de Mesquita Filho (UNESP). Araçatuba, SP, Brasil. agarbin@foa.unesp.br Patrick Raphael Vicente Gonçalves. Universidade Estadual Paulista Júlio de Mesquita Filho (UNESP). Araçatuba, SP, Brasil. patrick.raphael@hotmail. com

Cléa Adas Saliba Garbin. Universidade Estadual Paulista Júlio de Mesquita Filho (UNESP). Araçatuba, SP, Brasil. cgarbin@foa.unesp.br

\section{Resumo}

Objetivo: identificar a relação entre o nível de conhecimento dos agentes comunitários de saúde sobre saúde bucal e a presença da Equipe de Saúde Bucal na Estratégia Saúde da Família. Métodos: uma pesquisa tipo inquérito foi realizada com 173 agentes comunitários de saúde alocados na rede pública de saúde em cinco municípios da região noroeste do estado de São Paulo, Brasil, por meio de um questionário autoaplicável, estruturado. 0 instrumento da pesquisa contemplava perguntas referentes à presença da Equipe de Saúde Bucal na Estratégia Saúde da Família e questões sobre saúde bucal. Resultados: a maioria dos agentes comunitários de saúde estava inserida em estratégias com a presença de Equipes de Saúde Bucal $(60,1 \%)$. Verificou-se que o conhecimento em saúde bucal da maioria dos participantes foi bom (48\%). Conclusão: existe relação entre o nível de conhecimento dos agentes comunitários de saúde e a presença da Equipe de Saúde Bucal na Estratégia Saúde da Família.

\section{Abstract}

Objective: to identify the relation between the level of knowledge of community health workers on oral health and the presence of the Oral Health Team in the Family Health Strategy. Methods: we performed a survey with 173 community health workers allocated in public health services of five municipalities in the northwest of São Paulo, Brazil, through a self-administered and structured instrument. The survey instrument contemplated questions related to the presence of the Oral Health Team in the Family Health Strategy and questions regarding oral health. Results: the majority of community health workers was inserted in strategies with the presence of Oral Health Teams $(60.1 \%)$. We found that the oral health knowledge of most participants was good (48\%). Conclusion: there is relation between the level of knowledge of community health workers and the presence of the Oral Health Team in the Family Health Strategy.

\section{Resumen}

Objetivo: identificar la relación del nivel de conocimiento de los agentes comunitarios de salud sobre salud bucal y la presencia del Equipo de Salud Bucal en la Estrategia Salud de la Familia. Métodos: se realizó una investigación tipo encuesta con 173 agentes comunitarios de salud de la red pública de salud en cinco municipios de la región noroeste del estado de São Paulo, Brasil, por medio de un cuestionario autoaplicable, estructurado. El instrumento de recogida de datos tenía preguntas sobre la presencia del Equipo de Salud Bucal en la Estrategia Salud de la Familia y cuestiones sobre salud bucal. Resultados: la mayoría de los agentes comunitarios de salud estaba inserta en estrategias con la presencia de equipos de salud bucal $(60,1 \%)$. Se observó un buen conocimiento sobre salud bucal en la mayoría de los participantes (48\%). Conclusión: hay relación entre el nivel de conocimiento de los agentes comunitarios de salud y la presencia del Equipo de Salud Bucal en la Estrategia Salud de la Familia.

\section{Palavras-chave:}

Agentes Comunitários de Saúde Saúde da Família Saúde Bucal

\section{Keywords:} Community Health Workers Family Health Oral Health

Palabras clave: Agentes Comunitarios de Salud Salud de la Familia Salud Bucal

\section{Fonte de financiamento:} declaram não haver. Parecer CEP: UNESP FOA-01460/2011 24/10/2011

\section{Conflito de interesses:} declaram não haver. Recebido em: 24/06/2013. Aprovado em: 09/01/2014. 


\section{Introdução}

O trabalho dos agentes comunitários de saúde (ACS) iniciou-se a partir do Programa de Agentes de Saúde (PAS) em 1987, originado por meio do Programa Emergencial no Estado do Ceará, que ocorreu entre junho de 1987 e junho de 1988, em função da seca ${ }^{1}$. A repercussão do trabalho realizado pelos agentes de saúde foi táo significativa que o Ministério da Saúde, em 1991, decidiu criar o Programa de Agentes Comunitários de Saúde (PACS), com o intuito de estimular o autocuidado por meio de repasse de informaçôes, contemplando a prevenção, a promoção da saúde e a ampliação do acesso ao sistema de saúde. ${ }^{1,2}$

O PACS representou a etapa transitória para a criação do Programa Saúde da Família (PSF) em 1994, posteriormente denominado de Estratégia Saúde da Família (ESF), com a finalidade de reorganizar a Atenção Primária à Saúde no país, priorizando as açôes de promoçáo e recuperaçáo da saúde das pessoas, de forma integral e contínua, tendo como eixo de trabalho a prática da vigilância em saúde, pautado nos princípios do Sistema Único de Saúde (SUS) - universalidade, equidade e integralidade - e seus princípios organizacionais - hierarquização, descentralização, regionalização, participação e controle social. ${ }^{2,3}$

Nesse contexto, o ACS assume um papel crucial na implantação e na funcionalidade da ESF, visto ser o elo entre a comunidade e os serviços de saúde. Por residir no mesmo local em que trabalha, proporciona o contato permanente com a população assistida, partilhando, normalmente, do mesmo status socioeconômico e das experiências sociais e culturais da comunidade a que serve. ${ }^{4} \mathrm{O}$ contato entre o ACS e a comunidade é estabelecido por meio das visitas domiciliares, permitindo o conhecimento das reais condições de saneamento, moradia, educação, nutrição, lazer e trabalho das famílias. ${ }^{5}$

No intuito de ampliar o acesso da população às ações em saúde bucal, e considerando-a como parte integrante e indissociável da saúde do indivíduo, o Ministério da Saúde criou a Portaria GM/MS no 1.444, de 28 de dezembro de 2000, a qual regulamenta e estabelece incentivo financeiro para a reorganização da atenção à saúde bucal prestada nos municípios. ${ }^{6} \mathrm{Tal}$ portaria incluiu as Equipes de Saúde Bucal (ESB) na ESF e, consequentemente, acarretou um maior número de atribuiçôes aos deveres dos ACS, destacando-se o desenvolvimento de ações educativas e preventivas em saúde bucal. ${ }^{7}$

Frente a isso, o ACS, articulado à ESB, e devidamente capacitado, pode contribuir para fortalecer o conhecimento da população no enfrentamento dos problemas de saúde, além de auxiliar a equipe de saúde bucal na identificação das famílias mais vulneráveis que necessitam de açóes específicas e melhorar o acesso e a utilização dos serviços primários de saúde, a fim de evitar a assistência odontológica tardia, reduzindo a necessidade de consultas de urgência. ${ }^{8}$

Visto que a literatura apresenta poucos estudos que procuraram verificar a influência da realizaçáo de capacitaçáo dos agentes comunitários de saúde pela Equipe de Saúde Bucal, e a relação da inserção desta com o nível de conhecimento dos ACS sobre saúde bucal, objetivou-se neste estudo identificar a relaçáo entre o nível de conhecimento dos agentes comunitários de saúde sobre saúde bucal e a presença da Equipe de Saúde Bucal na Estratégia Saúde da Família em cinco municípios do estado de São Paulo, Brasil.

\section{Métodos}

Trata-se de um estudo censitário, transversal, com uma abordagem quantitativa, onde a população do estudo foi constituída por todos os agentes comunitários de saúde dos municípios de Araçatuba, Bilac, Birigui, Coroados e Glicério, localizados na região noroeste do estado de São Paulo, Brasil e pertencentes ao Departamento Regional de Saúde II (DRS II) - Araçatuba.

Inicialmente, foram contactados os gestores do sistema de saúde dos municípios pesquisados para informá-los a respeito do objetivo do estudo e do posterior uso dos dados coletados, a fim de obter apoio para a realizaçáo do estudo. Posteriormente, foi realizado um pré-teste do instrumento com $10 \%$ do universo da pesquisa, em municípios distintos aos pesquisados. Os resultados foram analisados com base no estudo de Andrade et al (2008), ${ }^{9}$ onde a caracterização do nível de conhecimento dos ACS foi baseada no percentual de acertos.

Para a coleta dos dados, foi utilizado um questionário estruturado, autoaplicável, composto por questóes referentes à presença do cirurgião-dentista na ESF, realização de capacitação em saúde bucal e o responsável pela mesma, percepção da necessidade de mais informaçóes sobre o tema, açóes e atividades educativas e preventivas em saúde bucal realizadas nas famílias e o responsável por essas práticas, orientaçôes sobre higienização bucal da população, presença de material educativo 
e questôes específicas sobre assuntos relacionados à odontologia. Essas questôes se apresentavam nos seguintes formatos: afirmaçóes do tipo "Os dentes de leite não precisam ser tratados porque serão substituídos pelos dentes permanentes", dando como possibilidade de resposta "certo ou errado"; questóes de múltipla escolha como "O primeiro molar permanente, conhecido como molar dos 6 anos, erupciona:" "atrás do último molar temporário (dente de leite)", "substitui um dente temporário (de leite)", ou "não sei"; e questóes que procuravam analisar o conhecimento sobre saúde bucal, como "Você sabe o que é placa dental?", dando como possibilidade de resposta "sim" ou "não". No caso de a resposta ser afirmativa, pedia-se para que fosse explicado o significado do termo mencionado. A análise dessas respostas foi realizada com base na literatura atual, julgando como "errada" na tabulação dos dados apenas a resposta dada que fugia completamente ao tema.

A fim de obter um escore a partir do número de acertos que representasse o nível de conhecimento do ACS, foram somadas as respostas corretas seguindo os critérios de classificação: insuficiente (até 24\% de acertos), regular (25 a $49 \%$ de acertos), bom (50 a 74\% de acertos) e ótimo (75 a 100\% de acertos). ${ }^{9} 10$

Os dados coletados foram tabulados por meio do programa Epi Info, versão 3.5.2, analisados estatisticamente por meio do teste qui-quadrado de Pearson, com nível de significância de 5\%, e apresentados em frequências absolutas e percentuais.

O trabalho foi conduzido dentro dos padrôes exigidos pela Resolução 196/CNS e aprovado pelo Comitê de Ética em Pesquisa em Seres Humanos da Faculdade de Odontologia de Araçatuba-UNESP, processo FOA - 01460/2011. Os ACS que aceitaram participar do estudo foram informados em relação à finalidade e ao sigilo das informaçóes coletadas e assinaram o Termo de Consentimento Livre e Esclarecido.

\section{Resultados}

A população do estudo era composta pelos 307 ACS dos cinco municípios integrantes da pesquisa, sendo que 173 sujeitos $(56,4 \%)$ aceitaram responder ao questionário. Os demais recusaram a participação no estudo ou se encontravam em período de férias. As perdas foram similares nos dois grupos pesquisados (ESF com ou sem ESB implantada).

Destes ACS, a maioria era do sexo feminino, tinha de 40 a 49 anos de idade (29,5\%) e atuava como ACS há 3 ou 4 anos $(39,9 \%)$ (Tabela 1).

Tabela 1. Sexo, faixa etária e tempo de serviço dos agentes comunitários de saúde.

\begin{tabular}{lcc}
\hline \multicolumn{1}{l}{ Gênero } & $\mathbf{n}$ & $\mathbf{\%}$ \\
$\quad$ Masculino & 10 & 5,8 \\
$\quad$ Feminino & 163 & 94,2 \\
Faixa etária & & \\
$<20$ anos & 1 & 0,6 \\
$20-29$ anos & 35 & 20,2 \\
$30-39$ anos & 50 & 28,9 \\
$40-49$ anos & 51 & 29,5 \\
Mais de 50 anos & 36 & 20,8 \\
Tempo de atuação como ACS & & \\
$1-2$ anos & 64 & 37 \\
$3-4$ anos & 69 & 39,9 \\
$5-7$ anos & 18 & 10,4 \\
$8-10$ anos & 19 & 11 \\
Mais de 10 anos & 3 & 1,7 \\
\hline
\end{tabular}

A maior parcela dos agentes comunitários de saúde avaliada estava inserida em estratégias com ESB (60,1\%). A maioria relatou não ter sido capacitada (63\%) e sentir a necessidade de um maior conhecimento sobre saúde bucal (86,1\%), além de não possuir nenhum tipo de material educativo $(86,1 \%)$ (Tabela 2$)$. 
Tabela 2. Presença do cirurgião-dentista (CD) na ESF, realização de capacitação em saúde bucal, ações sobre saúde bucal realizadas pela equipe, percepção da necessidade de mais informações pelo ACS e disponibilidade de material informativo.

\begin{tabular}{lcc}
\hline & $\mathbf{n}$ & $\mathbf{\%}$ \\
\hline $\begin{array}{l}\text { Presença do CD na Estratégia Saúde da Família } \\
\text { Sim }\end{array}$ & 104 & 60,1 \\
Não & 69 & 39,9 \\
Capacitação em Saúde Bucal & & \\
$\quad$ Sim & 64 & 37 \\
Não & 109 & 63 \\
Realização de orientações em Saúde Bucal & & \\
$\quad$ Sim & 63 & 36,4 \\
Não & 110 & 63,6 \\
Percepção da necessidade de mais informações sobre o tema & & \\
$\quad$ Sim & 149 & 86,1 \\
$\quad$ Não & 24 & 13,9 \\
Responsável pelas atividades preventivas em saúde bucal & & \\
$\quad$ Não realiza & 66 & 38,1 \\
ACS & 9 & 5,2 \\
Cirurgião-Dentista & 95 & 54,9 \\
Enfermeiro & 2 & 1,2 \\
Médico & 1 & 0,6 \\
Disponibilidade de material educativo & & \\
Sim & 24 & 13,9 \\
Não & 149 & 86,1 \\
\hline
\end{tabular}

Com relação às questôes referentes à saúde bucal, 164 ACS (94,8\%) não sabiam que a técnica de escovação indicada para crianças era diferente da técnica para adultos; 120 (69,4\%) desconheciam que o primeiro molar permanente erupciona atrás do último molar temporário ("dente de leite"); 104 (60,1\%) não compreendiam a causa do sangramento gengival; $100(57,8 \%)$ não souberam responder o que é placa bacteriana e 93 (53,8\%), o que é a cárie dentária. Além disso, 85 ACS $(49,1 \%)$ desconheciam a quantidade ideal de pasta dentária que deve ser colocada na escova de dentes, $78(45,1 \%)$ não sabiam como ensinar o indivíduo adulto a escovar e 73 (42,2\%) náo souberam responder o número de vezes que os dentes devem ser escovados diariamente, tampouco as características ideais da escova. Dos participantes da pesquisa, 64 ACS (37\%) desconheciam a importância da utilização do flúor para prevenção da cárie dentária, $56(32,4 \%)$ não souberam informar quais os alimentos mais prejudiciais à saúde bucal, 59 (34,1\%) não souberam dizer qual é o período do dia em que se deve ter maior atenção na escovação dentária, $41 \mathrm{ACS}(23,7 \%)$ não souberam explicar a importância do uso do fio dental, $37(21,4 \%)$ não conheciam as funçóes dos dentes, $32(18,5 \%)$ não compreendiam que os "dentes de leite" precisam ser tratados apesar de substituídos pelos dentes permanentes e $21(12,2 \%)$ desconheciam que os alimentos açucarados poderiam ser consumidos, desde que fosse realizada a escovação dos dentes após esse tipo de alimentaçáo.

De acordo com o critério utilizado para classificar o conhecimento em saúde bucal dos integrantes do estudo, foi observada a predominância do conceito "BOM" (48\% dos questionários), seguido do "REGULAR" (26\%), "ÓTIMO" $(13,3 \%)$ e "RUIM" (12,7\%).

Por meio do teste do qui-quadrado, foi detectada associação estatisticamente significativa da capacitação recebida e da presença da ESB na ESF com o nível de conhecimento em saúde bucal dos ACS (Tabelas 3 e 4).

Tabela 3. Associação entre o conceito obtido pelos pesquisados e a realização de capacitação em saúde bucal pelo agente comunitário de saúde (ACS).

\begin{tabular}{ccccccc}
\hline \multirow{2}{*}{ Conceito } & \multicolumn{2}{c}{ Realizaram capacitação em saúde bucal } & Não realizaram capacitação em saúde bucal & \multicolumn{2}{c}{ Total } \\
\cline { 2 - 7 } & $\mathrm{n}$ & Porcentagem & $\mathrm{n}$ & Porcentagem & $\mathrm{n}$ & Porcentagem \\
\hline Insuficiente & 0 & 0 & 19 & 100 & 83,8 & 19 \\
Regular & 6 & 16,2 & 31 & 52,2 & 69 & 100 \\
Bom & 33 & 47,8 & 36 & 47,9 & 48 & 100 \\
Ótimo & 25 & 52,1 & 23 & 63 & 173 & 100 \\
Total & 64 & 37 & 109 & & & 100 \\
\hline
\end{tabular}

${ }^{*}$ Qui-quadrado $=26,17$ e valor $p<0,001$. 
Tabela 4. Associação entre o conceito obtido pelos pesquisados e a presença da Equipe de Saúde Bucal (ESB) na Estratégia Saúde da Família (ESF).

\begin{tabular}{|c|c|c|c|c|c|c|}
\hline \multirow{2}{*}{ Conceito } & \multicolumn{2}{|c|}{ ESF com ESB implantada } & \multicolumn{2}{|c|}{ ESF sem ESB implantada } & \multicolumn{2}{|c|}{ Total } \\
\hline & $\mathrm{n}$ & Porcentagem & $\mathrm{n}$ & Porcentagem & $\mathrm{n}$ & Porcentagem \\
\hline Insuficiente & 0 & 0 & 19 & 100 & 19 & 100 \\
\hline Regular & 12 & 32,4 & 25 & 67,6 & 37 & 100 \\
\hline Bom & 51 & 73,9 & 18 & 26,1 & 69 & 100 \\
\hline Ótimo & 40 & 83,3 & 8 & 16,7 & 48 & 100 \\
\hline Total & 103 & 59,5 & 70 & 40,5 & 173 & 100 \\
\hline
\end{tabular}

${ }^{*}$ Qui-quadrado $=56,44$ e valor $p<0,001$.

\section{Discussão}

O medo de se tratar de fiscalização por parte do poder executivo, ou perseguição política, ou ainda o receio de ser observado e veiculado o desconhecimento e a não realização por parte dos agentes comunitários de saúde de açóes e atividades inerentes ao seu trabalho, pode explicar em parte a não participação desses trabalhadores na pesquisa, apesar de explicitado que os dados em hipótese alguma seriam divulgados de maneira individual ou identificados. ${ }^{11}$ Uma taxa de resposta de pelo menos 50\% é considerada adequada para análise e relatório, embora esta seja uma regra rudimentar e sem base estatística, sendo considerada a ausência de viés de resposta mais importante do que uma alta taxa de resposta. ${ }^{12}$

O ACS é um personagem da própria comunidade, que se identifica com ela em seus aspectos sociais e culturais, pois reside na área onde trabalha, o que define um envolvimento singular com os problemas que acometem a saúde das famílias assistidas. $^{13}$

A grande maioria dos ACS participantes da pesquisa era do gênero feminino, corroborando outros estudos, ${ }^{7,8,14,15}$ o que sugere a adequação do gênero a essa categoria profissional. A ação próxima às famílias e a habilidade advinda do processo de socialização feminino são elementos que justificam a presença e a seletividade de sexo/gênero nos processos de contratação para essa atividade. ${ }^{14}$ Tal característica apresenta-se como uma condiçáo favorável para o desenvolvimento das atividades realizadas, uma vez que as mulheres possuem maior sensibilidade para entender e enfrentar os problemas da comunidade. ${ }^{5}$

Segundo o Ministério da Saúde, um dos pré-requisitos para exercer a função de ACS é ter pelo menos 18 anos de idade, não sendo estabelecido um limite máximo de idade ${ }^{16}$ No presente estudo, foi verificado o predomínio de ACS nas idades adulta e meia idade e que apresentavam pequeno tempo de atuação na ESF.

O tempo de atuação na ESF é considerado crucial para o entendimento do trabalho do ACS, que é pautado em suas práticas cotidianas. Nesse contexto, acredita-se que o conhecimento em relação à comunidade, os vínculos e os laços de amizade aumentem com a idade do ACS, apesar de esses trabalhadores mais velhos serem mais resistentes a novos conceitos e tendências, diferentemente dos mais jovens, onde há maior maleabilidade a mudanças e conceitos. ${ }^{17}$

O trabalho desenvolvido pelos ACS é pautado por meio do desenvolvimento de açôes primárias em saúde e atividades de caráter educativo. ${ }^{18}$ Entretanto, os resultados encontrados demonstram que poucos ACS eram os agentes responsáveis pelas açôes de caráter educativo em saúde bucal e que a menor parcela dos entrevistados repassava orientações sobre higiene bucal para as famílias pelas quais eram responsáveis. Tais achados divergem do estudo realizado por Holanda, Barbosa e Brito, ${ }^{19}$ que evidenciaram os ACS como responsáveis pela execução de atividades educativas em saúde bucal, mesmo diante da insegurança em repassar tais informaçôes.

Para que o ACS possa influenciar positivamente no conhecimento em saúde bucal da população pela qual é responsável e, consequentemente, aumentar a conscientização dessas pessoas para a questão do autocuidado, é necessário que esse trabalhador esteja devidamente capacitado para desenvolver tais açóes. No entanto, a formação original do ACS, usualmente vinculada à categoria de enfermagem e médica, contribui para o distanciamento de relaçóes entre os cirurgiôes-dentistas e os ACS, dificultando a realização de açôes em saúde bucal por esses trabalhadores. ${ }^{19}$ Tal fato reforça a fragmentação da equipe e o desafio da visão interdisciplinar da saúde.

De acordo com alguns estudos, ${ }^{20,21}$ os cirurgióes-dentistas atuantes na ESF possuem perfil voltado para a clínica, aspecto que está relacionado à sua formação acadêmica centrada nas práticas tradicionais. Além disso, executam suas funçôes de forma fragmentada, com base no modelo curativo, o que não permite a articulação das açốes entre os membros da equipe de maneira sistemática. 
Os cirurgiōes-dentistas que compóem as ESB devem compreender a importância que os agentes comunitários de saúde assumem na resolução dos principais problemas de saúde bucal ${ }^{5}$ Cabe a esses profissionais repassar informações sobre saúde bucal para os ACS, proporcionando aos mesmos conhecimentos suficientes para atuarem como agentes multiplicadores de informações na comunidade, a fim de melhorar a higienização, diminuir os índices de cárie, detectar precocemente o câncer de boca e aumentar a qualidade de vida das famílias. ${ }^{5}$

Para que o cirurgião-dentista possa fornecer ao ACS uma capacitação em saúde bucal pautada nos princípios do Sistema Único de Saúde, torna-se necessário uma formação acadêmica com experiências vividas por meio da integração entre ensino-serviço, o que contribui, não somente para a compreensão da realidade, mas também para o crescimento profissional e comprometimento com as mudanças sociais necessárias, permitindo visualizar os fatores relevantes que influenciam o processo saúde-doença. ${ }^{22,23}$ Nesse contexto, é importante salientar que a qualificação profissional e a dedicação exclusiva ao sistema público de saúde demonstram características de perfil profissional singulares e condizentes com as exigências do trabalho junto à Estratégia Saúde da Família. ${ }^{24}$

A realização de capacitação e a presença do cirurgião-dentista na equipe de saúde da família influenciaram positivamente no conhecimento em saúde bucal do ACS, fato observado no presente estudo. Corroborando tais achados, Frazão e Marques ${ }^{25}$ verificaram a influência da capacitação do ACS na percepção de saúde bucal de mulheres e mães, onde se obteve significativas mudanças nos conhecimentos apresentados, tanto pelo grupo de ACS, quanto pelo grupo de mulheres e mães, efeito atribuído às açóes destes trabalhadores por meio de visitas domiciliares.

Os resultados encontrados no presente trabalho mostraram que a população estudada apresentava deficiências em determinados assuntos relacionados à saúde bucal e que a maior parte dos ACS não teve nenhum tipo de capacitação em relação ao tema. O aperfeiçoamento técnico-científico do ACS, de forma continuada, é fundamental para o aprimoramento de suas habilidades e aquisição de novas competências. ${ }^{18}$ Devem ser pensadas estratégias de ação que proporcionem um reforço contínuo dos sujeitos envolvidos no processo e da população, com a ajuda de instrumentos educativos variados, já que a educação deve ser pensada como um processo capaz de desenvolver nos indivíduos a consciência crítica das reais causas de seus problemas, criando um espírito para mudança; de transformar atitudes e comportamentos; de formar hábitos na população em benefício de sua própria saúde; além de permitir uma reflexão sobre as condiçóes reais de vida das pessoas. ${ }^{26,27}$

É fundamental que os gestores do sistema de saúde municipal facilitem a realização de capacitaçôes periódicas em saúde bucal, a fim de proporcionar aos ACS a possibilidade de contribuir de maneira mais eficaz nas açóes de promoção, prevenção e recuperação da saúde. Além disso, devem fornecer materiais educativos de saúde bucal para compor o arsenal de conhecimento a ser repassado à população assistida pela ESF.

\section{Conclusão}

Embora seja possível que o resultado não represente o nível de conhecimento da totalidade dos pesquisados, sugere-se que existe relação entre o nível de conhecimento dos agentes comunitários de saúde e a presença da Equipe de Saúde Bucal na Estratégia Saúde da Família. Compreende-se que a constante capacitação dos ACS possibilitará que as açôes e atividades em saúde bucal sejam desenvolvidas com maior eficácia, melhorando a qualidade de vida da população assistida.

\section{Referências}

1. Ávila MMM. O programa de agentes comunitários de saúde no Ceará: o caso de Uruburetama. Ciênc Saúde Coletiva. 2011;16(1):349-60. Disponível em: http://dx.doi.org/10.1590/S1413-81232011000100037.

2. Melo MB, Brant LC, Oliveira LA, Santos APS. Qualificação de agentes comunitários de saúde: instrumento de inclusão social. Trab Educ Saúde. 2010;7(3):463-77. Disponível em: http://dx.doi.org/10.1590/S1981-77462009000300005.

3. Cericato GO, Garbin D, Fernandes APS. A inserção do cirurgião-dentista no PSF: uma revisão crítica sobre as ações e os métodos de avaliação das Equipes de Saúde Bucal. RFO UPF. 2007 [acesso em 2013 Jan 10];12(3):18-23. Disponível em: http://www.upf.br/seer/index.php/rfo/article/view/1065.

4. Figueiredo MFS, Rodrigues Neto JF, Leite MTS. Educação em saúde no contexto da Saúde da Família na perspectiva do usuário. Interface Comun Saúde Educ. 2012;16(41):315-29. Disponível em: http://dx.doi.org/10.1590/S1414-32832012000200003.

5. Moura MS, Carvalho CJ, Amorim JTC, Marques MFSS, Moura LFAD, Mendes RF. Perfil e práticas de saúde bucal do agente comunitário de saúde em municípios piauienses de pequeno porte. Ciênc Saúde Coletiva. 2010;15(Supl. 1):1487-95. Disponível em: http://dx.doi.org/10.1590/S1413-81232010000700061. 
6. Ministério da Saúde (BR), Secretaria Executiva. Programa Saúde da Família: equipes de saúde bucal. Brasilia: Ministério da Saúde; 2002.

7. Mialhe FL, Lefevre F, Lefevre AMCO. O agente comunitário de saúde e suas práticas educativas em saúde bucal: uma avaliação qualiquantitativa. Ciênc Saúde Coletiva. 2011;16(11):4425-32. Disponível em: http://dx.doi.org/10.1590/S1413-81232011001200015.

8. Frazão P, Marques D. Efetividade de programa de agentes comunitários na promoção da saúde bucal. Rev Saúde Pública. 2009:43(3):463-71. Disponível em: http://dx.doi.org/10.1590/S0034-89102009005000016.

9. Andrade RD, Mello DF, Scochi CGS, Fonseca LMM. Jogo educativo: capacitação de agentes comunitários de saúde sobre doenças respiratórias infantis. Acta Paul Enferm. 2008;21(3):444-8. Disponível em: http://dx.doi.org/10.1590/S0103-21002008000300010.

10. Fonseca LMM, Scochi CGS, Mello DF. Educação em saúde de puérperas em alojamento conjunto neonatal: aquisição de conhecimento mediado pelo uso de um jogo educativo. Rev Latino-Am Enfermagem. 2002;10(2):166-71. Disponível em: http://dx.doi.org/10.1590/S0104-11692002000200007.

11. Martins RJ, Moimaz SAS, Garbin CAS, Garbin AJI, Lima DC. Percepção dos coordenadores de saúde bucal e cirurgiões-dentistas do serviço público sobre o Sistema Único de Saúde (SUS). Saúde Soc. 2009;18(1):75-82. Disponível em: http://dx.doi.org/10.1590/S0104-12902009000100008.

12. Babbie E. Métodos de pesquisas de survey. Belo Horizonte: Editora UFMG; 1999. Questionários auto-administrados; p. 247-258.

13. Silva TB, Magalhães HLGO, Solá ACN, Rodrigues BC, Carneiro ACMO, Schechtman NP, et al. Capacitação do Agente Comunitário de Saúde na prevenção do Câncer de Colo Uterino. Rev Bras Educ Med. 2012 [acesso em 2013 Jan 10];36(Suppl.1):155-60. Disponível em: http://educa.fcc.org.br/scielo.php?script=sci_arttext\&pid=S1981-52712012000200021\&lng=es\&nrm=iso.

14. Imperatori G, Lopes MJM. Estratégias de intervenção na morbidade por causas externas: como atuam os agentes comunitários de saúde? Saúde Soc. 2009;18(1):83-94. Disponível em: http://dx.doi.org/10.1590/S0104-12902009000100009.

15. Coriolano MWL, Lima MM, Queiroga BAM, Ruiz-Moreno L, Lima LS. Educação permanente com agentes comunitários de saúde: uma proposta de cuidado com crianças asmáticas. Trab Educ Saúde. 2012;10(1):37-59. Disponível em: http://dx.doi.org/10.1590/S1981-77462012000100003.

16. Brasil. Ministério da Saúde. Programa de Agentes Comunitários de Saúde. Brasília: Ministério da Saúde; 2001.

17. Ferraz L, Aerts DRGC. O cotidiano de trabalho do agente comunitário de saúde no PSF em Porto Alegre. Ciênc Saúde Coletiva. 2005;10(2):347-55. http://dx.doi.org/10.1590/S1413-81232005000200012.

18. Koyashiki GAK, Alves-Souza RA, Garanhani ML. O trabalho em saúde bucal do Agente Comunitário de Saúde em Unidades de Saúde da Família. Ciênc Saúde Coletiva. 2008;13(4):1343-54. http://dx.doi.org/10.1590/S1413-81232008000400032.

19. Holanda ALF, Barbosa AAA, Brito EWG. Reflexões acerca da atuação do agente comunitário de saúde nas ações de saúde bucal. Ciênc Saúde Coletiva. 2009;14(Suppl. 1):1507-12. Disponível em: http://dx.doi.org/10.1590/S1413-81232009000800024.

20. Araújo YP, Dimenstein M. Estrutura e organização do trabalho do cirurgião-dentista no PSF de municípios do Rio Grande do Norte. Ciênc Saúde Coletiva. 2006;11(1):219-27. Disponível em: http://dx.doi.org/10.1590/S1413-81232006000100031.

21. Costa RM, Junior AM, Costa ICC, Pinheiro IVA. O trabalho em equipe desenvolvido pelo cirurgião-dentista na Estratégia Saúde da Família: expectativas, desafios e precariedades. Rev Bras Med Fam Comunidade 2012;7(24):147-63. Disponível em: http://dx.doi.org/10.5712/rbmfc7(24)434.

22. Pinheiro FMC, Nóbrega-Therrien SM, Almeida MEL, Almeida MI. A formação do cirurgião-dentista no Brasil: contribuições de estudos para a prática da profissão. RGO Rev Gaúcha Odontol 2009 [acesso em 2013 Jan 10];57(1):99-106. Disponível em: http://www.revistargo.com.br/ojs/index.php/revista/article/viewArticle/648.

23. Saliba NA, Saliba O, Moimaz SAS, Garbin CAS, Arcieri RM, Lolli LF. Integração ensino-serviço e impacto social em cinquenta anos de história da saúde pública na Faculdade de Odontologia da Universidade Estadual Paulista Júlio de Mesquita Filho. RGO Rev Gaúcha Odontol 2009 [acesso em 2013 Jan 10];57(4):459-65. Disponível em: http://www.revistargo.com.br/viewarticle.php?id=1366.

24. Costa SM, Prado MCM, Andrade TN, Araújo EPP, Silva Junior WS, Gomes Filho ZC, et al. Perfil do profissional de nível superior nas equipes da Estratégia Saúde da Família em Montes Claros, Minas Gerais, Brasil. Rev Bras Med Fam Comunidade 2013;8(27):90-6. Disponível em: http://dx.doi.org/10.5712/rbmfc8(27)530.

25. Frazão P, Marques DSC. Influência de agentes comunitários de saúde na percepção de mulheres e mães sobre conhecimentos de saúde bucal. Ciênc Saúde Coletiva 2006; 11(1):131-44. Disponível em: http://dx.doi.org/10.1590/S1413-81232006000100021.

26. Costa ICC, Albuquerque AJ. Educação para a saúde. In: Universidade Federal Do Rio Grande Do Norte. Odontologia preventiva e social: textos selecionados. Natal: EDUFRN; 1997. p. 223-50.

27. Petry PC, Pretto SM. Educação e motivação em saúde bucal. In: Kriger L, editor. ABOPREV: promoção de saúde bucal. $2^{a}$ ed. São Paulo: Artes Médicas; 1999. p. 363-70. 